\title{
Thermochromic properties of vanadium oxide films prepared by dc reactive magnetron sputtering
}

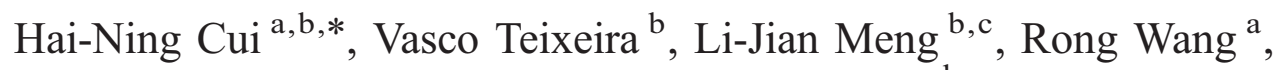 \\ Jin-Yue Gao ${ }^{a}$, Elvira Fortunato ${ }^{\mathrm{d}}$ \\ a College of Physics, JiLin University, 2519 JieFangDaLu Road, 130021 ChangChun, PR China \\ ${ }^{\mathrm{b}}$ Centro de Física e Departamento de Física, Universidade do Minho, 4710 Braga, Portugal \\ ${ }^{\mathrm{c}}$ Departamento de Física, Instituto Superior de Engenharia do Porto, Rua de São Tomé, 4200 Porto, Portugal \\ ${ }^{\mathrm{d}}$ Dept. Ciência dos Materiais, CENIMAT, Faculdade de Ciências e Tecnologia da Universidade Nova de Lisboa, PT-2829-516 Caparica, Portugal
}

Available online 1 April 2007

\begin{abstract}
A transparent vanadium oxide film has been one of the most studied electrochromic (EC) and Thermochromic (TC) materials. Vanadium oxide films were deposited at different substrate temperatures up to $400^{\circ} \mathrm{C}$ and different ratios of the oxygen partial pressure $\left(P_{\mathrm{O} 2}\right)$. SEM, AFM and X-ray diffraction's results show detail structure data of the films. IR mode assignments of the films measured by IR reflection-absorbance in NGIA (near grazing incidence angle) are given. It is found that the film has $\mathrm{V}_{2} \mathrm{O}_{5}$ and $\mathrm{VO}_{2}$ combined structures. The films exhibit clear changes in transmittance when the environment temperature $\left(T_{\mathrm{e}}\right)$ is varied, especially in the $3600-4000 \mathrm{~cm}^{-1}$ range. Applying a $T_{\mathrm{e}}$ that is higher than a critical temperature $\left(T_{\mathrm{c}}\right)$ to the samples, the as-RT (room temperature) deposited film with $9 \% P_{\mathrm{O} 2}$ has a transmittance variation of $30 \%$, but the films that were deposited on a heated substrate of $400{ }^{\circ} \mathrm{C}$ have little variation. There is tendency of bigger variation in transmittance for the sample deposited at a larger $P_{\mathrm{O} 2}$, when it is applied by $200{ }^{\circ} \mathrm{C} T_{\mathrm{e}}$. (C) 2007 Elsevier B.V. All rights reserved.
\end{abstract}

Keywords: Vanadium oxide films; Thermochromic property; XRD; IR; dc magnetron sputtering

\section{Introduction}

A vanadium oxide film has been one of the most studied electrochromic (EC) and Thermochromic (TC) materials [1,2]. TC materials change reversibly color with changes in an environment temperature $\left(T_{\mathrm{e}}\right)$. They can be semi-conductor compounds, liquid crystals or metal compounds. TC materials change color by a process that is involved a chemical reaction of thermally inducement or a phase transformation. The change in color happens at a determined temperature, is called a critical temperature $\left(T_{\mathrm{c}}\right)$, which can be varied by doping materials. Thermochromism is seen in a large number of organic and certain inorganic compounds. Some of these compounds are $\mathrm{Fe}_{3} \mathrm{O}_{4}, \mathrm{NbO}_{2}, \mathrm{NiS}, \mathrm{Ti}_{2} \mathrm{O}_{3}, \mathrm{VO}_{2}$ and $\mathrm{V}_{2} \mathrm{O}_{5}$ [2]. Such material can be used to control transmittance and infrared emissivity of a

\footnotetext{
* Corresponding author. College of Physics, JiLin University, 2519 JieFangDaLu Road, 130021 ChangChun, PR China. Fax: +86 4318498071 or 5650478 .

E-mail address: hncui@yahoo.co (H.-N. Cui).
}

glazing, and also as thermotropic (TT) material which can cause a significant change in its electronic properties from an insulator to semiconductor transition or from a semiconductor to metallic state when the $T_{\mathrm{e}}$ exceeds the material's $T_{\mathrm{c}}$.

Vanadium has various valence states and results in a number of oxide forms of vanadium oxides. $\mathrm{V}_{2} \mathrm{O}_{3}, \mathrm{VO}_{2}$ and $\mathrm{V}_{2} \mathrm{O}_{5}$ films have been widely studied for optical, electrical, electrochemical,

Table 1

Deposition conditions, parameters and thermochromic properties of vanadium oxide films

\begin{tabular}{lcllllr}
\hline Sample & $P_{\mathrm{O} 2}(\%)$ & $T_{\mathrm{s}}\left({ }^{\circ} \mathrm{C}\right)$ & $\begin{array}{l}T_{\mathrm{a}} \\
\left({ }^{\circ} \mathrm{C}\right)\end{array}$ & $\begin{array}{l}\mathrm{IR}_{\text {at RT }} \\
(\%)\end{array}$ & $\begin{array}{l}\mathrm{IR}_{\text {at } 200{ }^{\circ} \mathrm{C}} \mathrm{T}_{\text {ts }} \\
(\%)\end{array}$ & $\begin{array}{l}\Delta \mathrm{IR} \mathrm{T}_{\text {ts }} \\
(\%)\end{array}$ \\
\hline V1 & 9 & $\mathrm{RT}$ & - & 79.0 & 49.0 & 30.0 \\
$\mathrm{~V} 2$ & 15 & 400 & - & 26.0 & 22.5 & 3.5 \\
$\mathrm{~V} 3$ & 20 & $\mathrm{RT}$ & - & 83.0 & 66.0 & 17.0 \\
V1a & 9 & $\mathrm{RT}$ & 400 & 27.5 & 16.0 & 11.5 \\
V3a & 20 & $\mathrm{RT}$ & 400 & 32 & 5 & 15.0 \\
V4a & 20 & RT & 200 & 53.0 & 14.0 & 39.0 \\
\hline
\end{tabular}

$\Delta$ IR: transmittance different at the $4000 \mathrm{~cm}^{-1}(2.5 \mu \mathrm{m})$ before and after the sample is put, into $200{ }^{\circ} \mathrm{C}$ temperature environment, $\Delta \mathrm{IR}=\mathrm{IR}_{\text {at }} 200{ }^{\circ} \mathrm{C}-\mathrm{IR}_{\mathrm{at}} \mathrm{RT}$. 


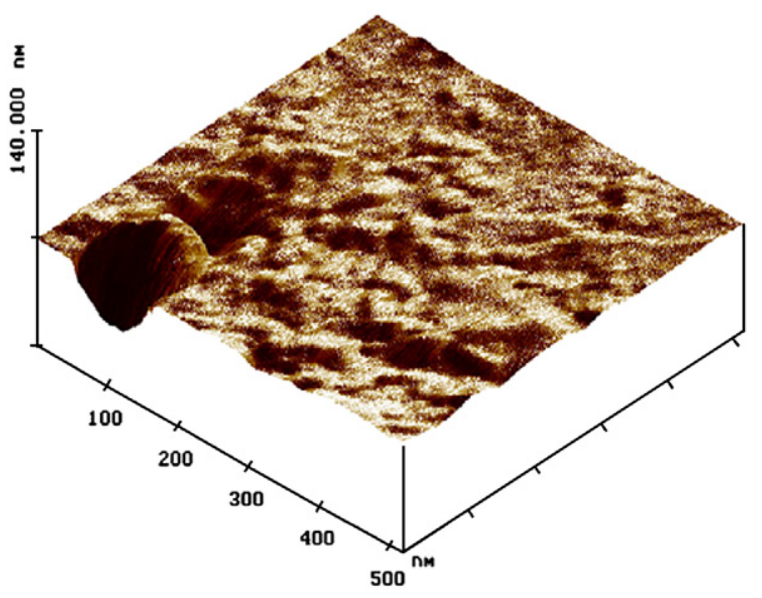

Fig. 1. Three dimensions (3D) AFM image of vanadium oxide film deposited with $9 \%$ oxygen partial pressure $\left(P_{\mathrm{O} 2}\right)$ at room temperature.

thermo-chromic and thermal switching materials. $\mathrm{VO}_{2}$ and $\mathrm{V}_{2} \mathrm{O}_{5}$ have been considered for window applications [3-6]. The interest in these materials has been increased in the last few years due to their potential applications in a wide variety of optical modulation devices.

Many research works have been focused on electrochromic coloration of this material, few works can be found on the study of the structure characterizations and thermochromic behaviours of vanadium oxide films. Different techniques have been used to synthesize vanadium oxide films, such as sputtering [7], thermal evaporation [4,5], pulse laser deposition [6], sol-gel [8] etc. Depending on the deposition conditions and techniques, films may present considerably different structural, optical and electrical character, and consequently different electrochromic and thermotropic behaviour. The sputtering is the most widely investigated and large-scale deposition set is available. With direct-current (dc) sputtering from a target Vanadium, thin film properties can be improved by controlling the reactive gas atmosphere and substrate temperature $\left(T_{\mathrm{s}}\right)$.

In this work, vanadium oxide films have been deposited onto glass substrates by dc reactive magnetron sputtering at different
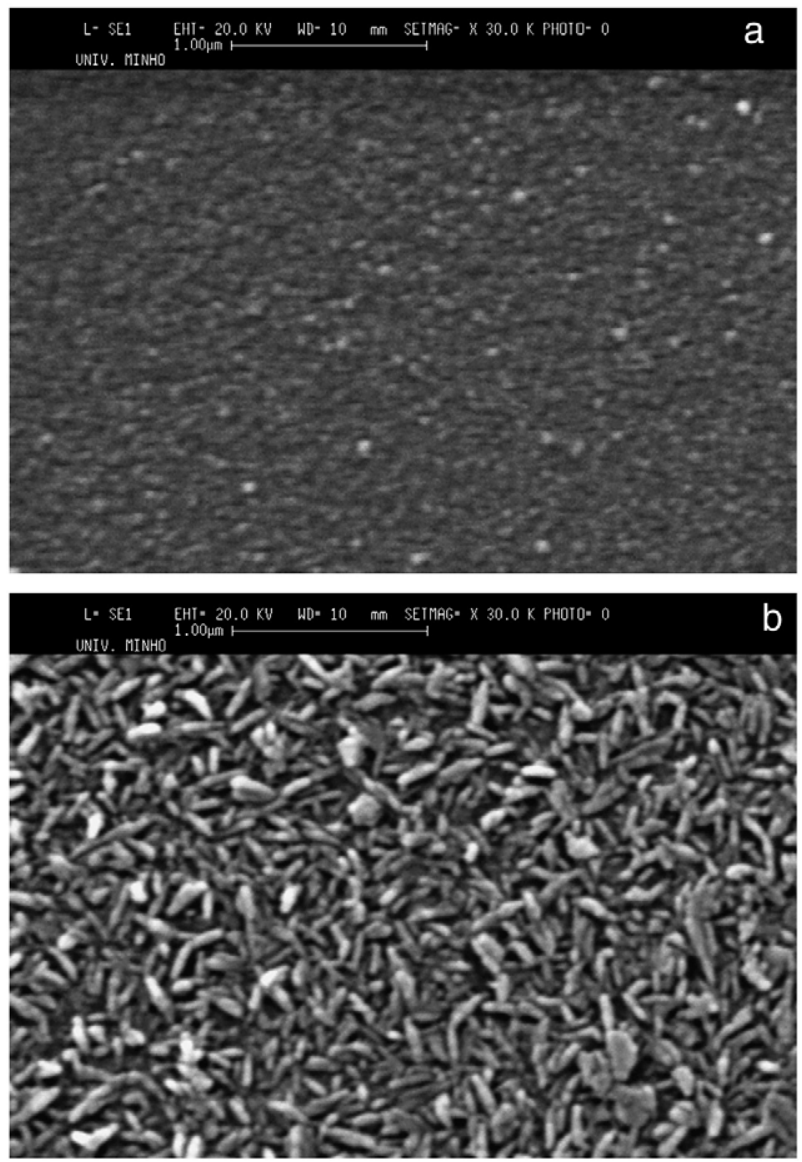

Fig. 3. SEM images of vanadium oxide films prepared at different depositing $T_{\mathrm{s}}$ (a) $100{ }^{\circ} \mathrm{C}$ and (b) $200{ }^{\circ} \mathrm{C}$; scale is $1 \mu \mathrm{m}$.

$T_{\mathrm{S}}$ and ratio of oxygen partial pressure $\left(P_{\mathrm{O} 2}\right)$. The structural and thermochromic properties of these films are studied.

\section{Experimental details}

Vanadium oxide films were deposited by using a home-made dc magnetron sputtering system. The target is a vanadium metal
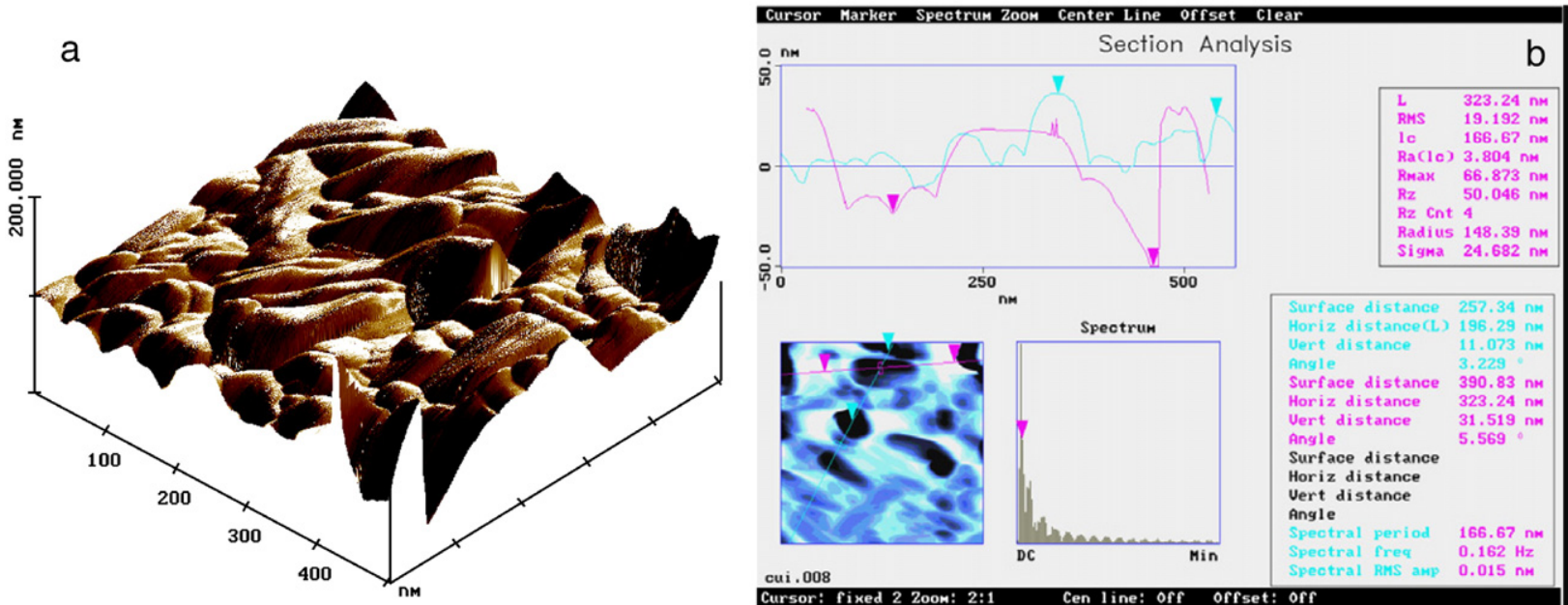

Fig. 2. AFM image (a) and section analysis (b) of vanadium oxide film deposited with $15 \% P_{\mathrm{O} 2}$ and at $400{ }^{\circ} \mathrm{C}$ depositing $T_{\mathrm{s}}$ for $20 \mathrm{~min}$. 




Fig. 4. X-ray diffraction spectra of vanadium oxide films deposited with $15 \%$ $P_{\mathrm{O} 2}$ at $400{ }^{\circ} \mathrm{C}$ depositing $T_{\mathrm{s}}(B)$, after $400{ }^{\circ} \mathrm{C}$ annealing $(C)$, and at room temperature deposition $(D)$.

disk (70 mm diameter) with a purity of $99.8 \%$. The vacuum chamber was evacuated down to pressure $1 \times 10^{-3} \mathrm{~Pa}$ prior to deposition. The sputtering gas (Ar) and reactive gas $\left(\mathrm{O}_{2}\right)$ were introduced into the chamber separately, and were controlled through two gas mass flow rate controllers. The ratio of oxygen partial pressure is defined as $P_{\mathrm{O} 2}=P\left(\mathrm{O}_{2}\right) /\left[P\left(\mathrm{O}_{2}\right)+P(\mathrm{Ar})\right]$, where $P\left(\mathrm{O}_{2}\right)$ and $P(\mathrm{Ar})$ are the oxygen and argon gas pressures respectively. The $P_{\mathrm{O} 2}$ can be adjusted in different experiments. The oxygen reactive gas was introduced into the chamber and the required pressure was set. Argon gas was introduced thereafter till the preset pressure was reached $(1 \mathrm{~Pa})$. The dc power during the film deposition was $160 \mathrm{~W}$. The temperature was varied from room temperature (RT) until $400{ }^{\circ} \mathrm{C}$.

The surface topology and cross-sectional structure of the films were observed by means of scanning electron microscopy (SEM, UK Leica-Cambrigde S360) and AFM (atomic force microscopy, Multimode TM SPM 3, Digital Instruments Nanoscope). In order to prevent charge build-up, a thin gold film was coated on the sample surface before SEM was carried out. The film X-ray diffractions (XRD) have been made using a Philips PW1710 computer-controlled diffractometer. $\mathrm{Cu} \mathrm{K}$ radiation from an $\mathrm{X}$-ray tube with normal focus was used. The film optical transmittance was measured by Shimadzu doublebeam spectrophotometer UV-3101PC. The ex-situ IR spectra of

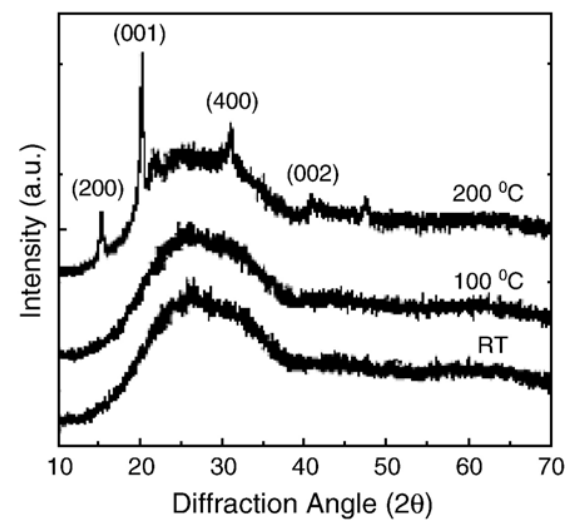

Fig. 5. X-ray diffraction patterns of vanadium oxide films prepared with $9 \% P_{\mathrm{O} 2}$ at different depositing $T_{\mathrm{s}}$.

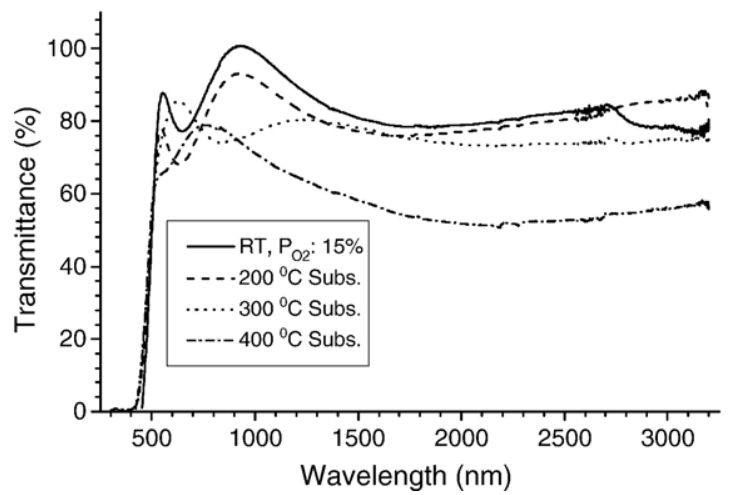

Fig. 6. Spectral transmittance of vanadium oxide films prepared at $15 \% P_{\mathrm{O} 2}$ (the ratio of oxygen partial pressure), and different depositing $T_{\mathrm{S}}$.

the films were obtained using a Fourier-transform infrared (FTIR) Bio-Rad FTS135 spectrometer (spectral range 4000$400 \mathrm{~cm}^{-1}$ ). Reflective absorption spectra in the mid-infrared were investigated in the films. The IR technique of reflective absorption is chose in case of near graze incidence angle (NGIA). The background spectra were scanned with an Al (aluminium) mirror as the reference. The resolution in wavenumber is $2 \mathrm{~cm}^{-1}$.

\section{Results and discussion}

\subsection{Structure characterizations of the films}

Vanadium oxide films were prepared at different $P_{\mathrm{O} 2}$, depositing $T_{\mathrm{s}}$, and annealing temperature $\left(T_{\mathrm{a}}\right)$. Some of them are listed in the Table 1 . The surface and the cross sectional morphologies of these films were analyzed (Figs. 1-3). The three dimensional (3D) AFM image of vanadium oxide films prepared at $9 \% P_{\mathrm{O} 2}$ and $\mathrm{RT}$ (sample: V1) is shown in Fig. 1. The finer morphology and roughness of the films can be clearly seen. The photography and AFM software analysis reveal a uniform growth of the film. The average grain size is less than $60 \mathrm{~nm}$. The films prepared at RT and $100{ }^{\circ} \mathrm{C}$ have relative smooth surface and very compact structure (Figs. 1 and $3 \mathrm{a}$ ).

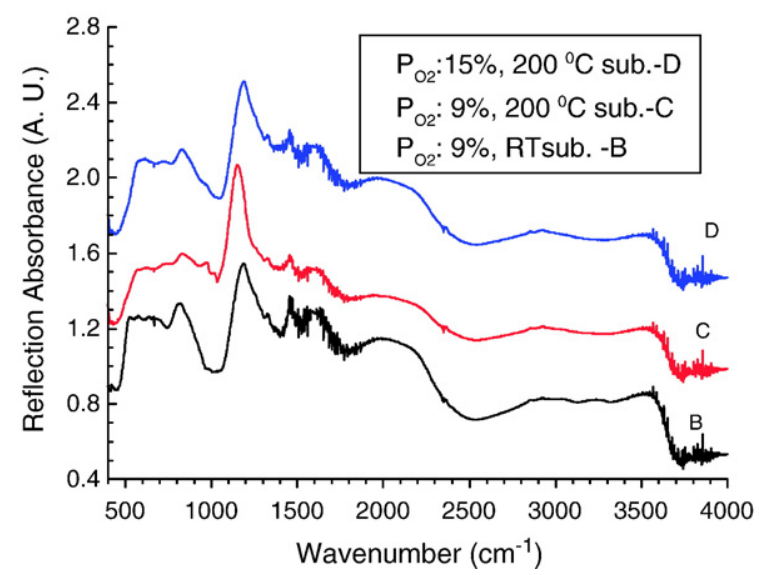

Fig. 7. IR spectra of the vanadium oxide films grown at room temperature and $200{ }^{\circ} \mathrm{C}$ depositing $T_{\mathrm{s}}$ with $9 \%$ and $15 \% P_{\mathrm{O} 2}$ respectively. 
Table 2

IR vibrational modes of the films (Wavenumbers: $\mathrm{cm}-1$ )

\begin{tabular}{lllll}
\hline Exp. & Assi. & $\mathrm{V}_{2} \mathrm{O}_{5}$ ref. & $\mathrm{VO}_{2}$ & $\mathrm{~V}_{2} \mathrm{O}_{3}$ ref. \\
\hline $418 \mathrm{w}$ & $v\left(3 \mathrm{~V}-\mathrm{O}_{\mathrm{C}}\right)$ & $412[17]$ & & \\
& & $490[18]$ & & \\
$509 \mathrm{~m}$ & $v\left(3 \mathrm{~V}-\mathrm{O}_{\mathrm{C}}\right)$ & $507[19]$ & & $508 \mathrm{sh}[20]$ \\
$517 \mathrm{~m}$ & & $512[20]$ & & $520 \mathrm{sh}[20]$ \\
$717 \mathrm{~m}$ & $v\left(\mathrm{~V}-\mathrm{O}_{\mathrm{b}}-\mathrm{V}\right)$ & $767[19]$ & $714 \mathrm{sh}[20]$ & \\
& & $784[18]$ & & \\
$804 \mathrm{~m}$ & $v\left(3 \mathrm{~V}-\mathrm{O}_{\mathrm{C}}\right)$ & $842[19]$ & & $980[20]$ \\
$816 \mathrm{~m}$ & & $828[20]$ & & \\
$970 \mathrm{~m}$ & & $975[17]$ & & \\
\hline
\end{tabular}

Exp.: experiment, ref.: reference, Assi.: assignment, m: medium, sh: shoulder peak, w: weak, Ter.: terminal.

Fig. 2(a) shows the AFM image of the vanadium oxide film deposited with $15 \% \mathrm{P}_{\mathrm{O} 2}$ at $400{ }^{\circ} \mathrm{C} T_{\mathrm{s}}$ (sample: V2) for $20 \mathrm{~min}$. It is clearly seen that there are much bigger quasi bar-shape grain formed in the film. Also it has a good uniformity revealing the uniform growth of the films. The average grain dimensions are less than $55 \times 135 \mathrm{~nm}$. Fig. 2(b) presents a section analysis and data determined by the AFM analysis. The maximum roughness and the average RMS (root mean square) roughness are 66.9 and $19.2 \mathrm{~nm}$. The grain size of the $\mathrm{V}_{2} \mathrm{O}_{5}$ film deposited at $400{ }^{\circ} \mathrm{C} T_{\mathrm{s}}$ is much bigger than that of the film annealed at $400{ }^{\circ} \mathrm{C}$. By the theory analysis [9] the bar-shaped grains may come from combining the effects of the direction of flowing field of the sputtering gas and the thermal field of high $400{ }^{\circ} \mathrm{C}$ $T_{\mathrm{s}}$. When the depositing $T_{\mathrm{s}}$ is increased and higher than $200^{\circ} \mathrm{C}$, the films show many small bar-shaped grains with the voids between them in SEM images of vanadium oxide films (Fig. 3). SEM images confirmed the AFM result.

In order to study the film structure, XRD spectra of the samples were measured and their patterns are shown in Figs. 4 and 5. Fig. 4 reveals the effects of post-treating $T_{\mathrm{a}}$ and depositing $T_{\mathrm{s}}$ of the vanadium oxide films deposited at $15 \%$ $P_{\mathrm{O} 2}$. For curve $(D)$ only very weak peaks plus a broad background from the glass substrate can be observed, which indicates that the film obtained at RT is amorphous. The films prepared at $400{ }^{\circ} \mathrm{C} T_{\mathrm{a}}$ have no sharp peak too; only very weak peaks of $\mathrm{V}_{2} \mathrm{O}_{5}(400), \mathrm{VO}_{2}\left(B^{\prime}\right)(002)$ and $\mathrm{V}_{2} \mathrm{O}_{5}(002)$ [10], plus

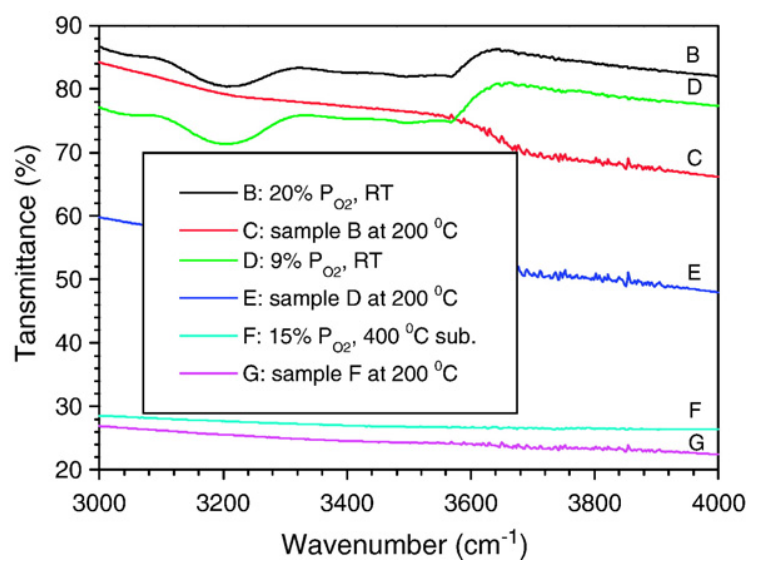

Fig. 8. IR spectra of vanadium oxide films (sample $\mathrm{V} 1=D ; \mathrm{V} 2=F ; \mathrm{V} 3=B$ ) deposited with different $P_{\mathrm{O} 2}$ before and after putting them into $200{ }^{\circ} \mathrm{C} T_{\mathrm{e}}$.

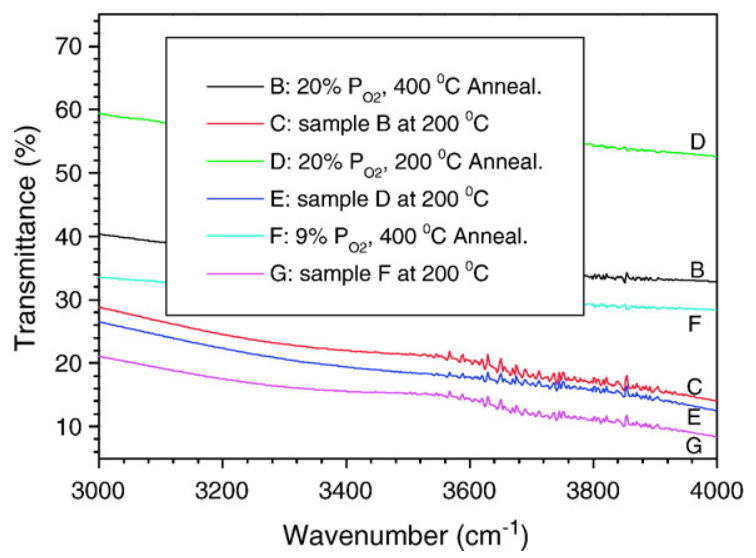

Fig. 9. IR spectra of the annealed vanadium oxide films (sample $\mathrm{V} 1 \mathrm{a}=F$; $\mathrm{V} 3 \mathrm{a}=B ; \mathrm{V} 4 \mathrm{a}=D$ ) before and after putting them into $200{ }^{\circ} \mathrm{C} T_{\mathrm{e}}$.

a broad background from the glass substrate are observed for the curve $(C)$, because the films are amorphous and thin. The spectrum $(B)$ shows the peaks that coincide with the $\mathrm{VO}_{2}\left(B^{\prime}\right)$ (001), $\mathrm{V}_{2} \mathrm{O}_{5}(001), \mathrm{V}_{2} \mathrm{O}_{5}(400)$, and $\mathrm{V}_{2} \mathrm{O}_{5}(002)$ [10,11]. $\mathrm{VO}_{2}$ $\left(B^{\prime}\right)$ is a metastable compound which can be converted into stable $\mathrm{VO}_{2}$ with a rutile or monoclinic structure in some conditions. Its structure is derived from the orthorhombic $\mathrm{V}_{2} \mathrm{O}_{5}$ by a crystallographic shear belonging to the same series as $\mathrm{V}_{6} \mathrm{O}_{13}$ [12]. $\mathrm{VO}_{2}\left(B^{\prime}\right)$ was reported to be an intermediate phase between $\mathrm{V}_{2} \mathrm{O}_{5}$ and $\mathrm{V}_{2} \mathrm{O}_{3}$ [11]. Although there are many possible phases of vanadium oxides, the $\mathrm{X}$-ray analysis revealed that the films are $\mathrm{VO}_{2}\left(B^{\prime}\right)$ and $\mathrm{V}_{2} \mathrm{O}_{5}$. The following IR result confirms the $\mathrm{XRD}$ analysis. All the films were strongly oriented with respect to $\mathrm{VO}_{2}\left(B^{\prime}\right)\{001\}, \mathrm{V}_{2} \mathrm{O}_{5}\{001\}$, and $\mathrm{V}_{2} \mathrm{O}_{5}\{100\}$. The structure correlates mainly with depositing $T_{\mathrm{s}}$ and little with annealing temperature.

The XRD measurements of Fig. 5 reveals that the films prepared at $9 \% P_{\mathrm{O} 2}$ and the depositing $T_{\mathrm{s}}$ lower than $200{ }^{\circ} \mathrm{C}$ are amorphous; and the film prepared at the $T_{\mathrm{s}}$ (higher than $200^{\circ} \mathrm{C}$ ) shows a polycrystalline structure [13]. When the $T_{\mathrm{s}}$ is higher than $300{ }^{\circ} \mathrm{C}$, the films show a random orientation. When the argon ions bombard the vanadium target, the pure vanadium atoms are sputtered and the kinetic energy is also transferred to them from the argon ions. Some of the sputtered vanadium atoms will impinge the substrate with some kinetic energy. However, with the power level in our experiments $(160 \mathrm{~W})$, the sputtered vanadium atoms can not get enough energy to form a crystalline $\mathrm{V}_{2} \mathrm{O}_{5}$ thin film on the substrate. Yoon et al. has reported that even $250 \mathrm{~W}$ dc power is not enough to grow a crystalline $\mathrm{V}_{2} \mathrm{O}_{5}$ thin film [14]. With increasing $T_{\mathrm{s}}$ the more energy will be supplied to the adatoms and results in an increasing of their mobility, which favor the recrystallization and increasing order of the microstructure. That is why the films prepared at high $T_{\mathrm{S}}$ have a crystalline structure and the films prepared at low $T_{\mathrm{s}}$ and RT with lower annealing temperature have an amorphous structure.

Fig. 6 shows the UV-VIS transmittance spectra of the films prepared at three different depositing $T_{\mathrm{s}}$. It could be clearly seen that the transmittance decreases as the depositing $T_{\mathrm{s}}$ is increased. From the Fig. 3 it can be seen that the sample surface become 
rough as the $T_{\mathrm{s}}$ is increased. The rough surface could result in a scattering light loss and then a low transmittance.

According to the results of the theoretical analysis, 21 modes of vibration are possible in the Raman and 15 in the IR spectrum of the $\mathrm{V}_{2} \mathrm{O}_{5}$. The effect of the deposition $P_{\mathrm{O} 2}$ of the film that was grown at $\mathrm{RT}$ and $200{ }^{\circ} \mathrm{C} T_{\mathrm{s}}$ in $15 \% P_{\mathrm{O} 2}$ and $9 \% P_{\mathrm{O} 2}$ is shown in Fig. 7. It is seen that the absorbance peaks 970 and $1020 \mathrm{~cm}^{-1}$ of the films become stronger after depositing at $200{ }^{\circ} \mathrm{C} T_{\mathrm{s}}$. The thickness increased a little and the color of the film changed from light yellow to yellow at the higher depositing $T_{\mathrm{s}}$.

The bands appearing at 970 and $1020 \mathrm{~cm}^{-1}$ correspond to the $\mathrm{V}$ (vanadium) $-\mathrm{O}_{\mathrm{v}}$ (vanadyl oxygen) stretching mode. The band between 700 and $900 \mathrm{~cm}^{-1}$ is assigned to the antisymmetric stretching vibration of the $\mathrm{V}-\mathrm{O}_{\mathrm{b}}-\mathrm{V}$ group $\left(\mathrm{O}_{\mathrm{b}}\right.$ : bridge oxygen). The group of band, which presents at $<600 \mathrm{~cm}^{-1}$ wavenumber, corresponds to the edge-shearing $3 \mathrm{~V}-\mathrm{O}_{\mathrm{c}}$ stretching and the bridging $\mathrm{V}-\mathrm{O}_{\mathrm{b}}-\mathrm{V}$ deformations $[10,15]$. The shift of the strong band between $1140 \mathrm{~cm}^{-1}$ and $1220 \mathrm{~cm}^{-1}$, which is assigned to $\delta(\mathrm{w}-\mathrm{O})$ in the $\mathrm{M}-\mathrm{OH} . . \mathrm{H}_{2} \mathrm{O}$ group, was observed as the plane deformational (bending) $\mathrm{M}-\mathrm{O}$ mode. Detailed assignment of these modes determined from the NGIA IR reflection-absorbance spectra and some data from other references are given in Table 2.

\subsection{Thermochromic properties of the films}

The IR transmittance spectra of the films are shown from $G$ in the $3000-4000 \mathrm{~cm}^{-1}(3.3-2.5 \mu \mathrm{m})$ range, before and after these samples are put into $200{ }^{\circ} \mathrm{C} T_{\mathrm{e}}$. The films exhibit clear changes in transmittance, especially in the range 3600$4000 \mathrm{~cm}^{-1}$. The variation of the transmittance arises due to the films change from a semiconductor phase to a metallic phase [16]. The data is summarized in the Table 1. Fig. 8 shows that after applying higher $T_{\mathrm{e}}\left(>T_{\mathrm{c}}\right.$ ) to the as-deposited films (sample $\mathrm{V} 1$; V2; V3) prepared with different $P_{\mathrm{O} 2}$ and depositing $T_{\mathrm{s}}$, the transmittance changes reaching a value up to $30 \%$. The films deposited at $400{ }^{\circ} \mathrm{C} T_{\mathrm{s}}$ show little variation. Fig. 9 shows that the $200{ }^{\circ} \mathrm{C} T_{\mathrm{a}}$ films (sample V1a; V3a; V4a) have strong transmittance variance, after applying higher $T_{\mathrm{e}}\left(>T_{\mathrm{c}}\right)$ to these samples that were deposited at different $P_{\mathrm{O} 2}$ and were treated at different $T_{\mathrm{a}}$. The maximum variation of the transmittance reaches $39 \%$ between sample $D$ and $E$ at $4000 \mathrm{~cm}^{-1}$ wavenumber.

\section{Conclusions}

AFM and SEM analysis show that vanadium oxide films prepared at RT and $100{ }^{\circ} \mathrm{C} T_{\mathrm{s}}$ are amorphous and compact. The film surface gets rough as the depositing $T_{\mathrm{s}}$ is increased. XRD of the sample reveals structural information of the film. An amorphous film was obtained at RT. Only very weak peaks of $\mathrm{V}_{2} \mathrm{O}_{5}$ plus a broad background from the glass substrate could be observed. The film prepared above $200{ }^{\circ} \mathrm{C} T_{\mathrm{S}}$ has a polycrystalline structure with a preferred orientation along the (001) direction. The films treated at $400{ }^{\circ} \mathrm{C} T_{\mathrm{a}}$ have no sharp peaks too in their X-ray diffraction spectra.
In the UV-VIS NIR studies it is found that as the depositing $T_{\mathrm{S}}$ increases from RT to $400{ }^{\circ} \mathrm{C}$, the transmittance of the films in the 300-3200 $\mathrm{nm}$ region decreases. The IR vibration results show that the absorbance peaks 970 and $1020 \mathrm{~cm}^{-1}$ of the films become stronger after depositing at $200{ }^{\circ} \mathrm{C} T_{\mathrm{s}}$ comparing with sample deposited at RT. The bands appearing at 970 and $1020 \mathrm{~cm}^{-1}$ correspond to the $\mathrm{V}$ (vanadium) $-\mathrm{O}_{\mathrm{v}}$ (vanadyl oxygen) stretching mode. All detailed assignment of these modes determined from the NGIA of IR reflection-absorbance spectra are given. The both XRD and IR results show a clear $\mathrm{V}_{2} \mathrm{O}_{5}$ and $\mathrm{VO}_{2}$ peaks for the vanadium oxide films.

These films were investigated for thermochromic applications. The film exhibits clear changes in transmittance when the $T_{\mathrm{e}}\left(>T_{\mathrm{c}}\right)$ of the sample is applied. The film deposited at RT and $9 \% P_{\mathrm{O} 2}$ has a transmittance variation of $30 \%$ before and after putting it into $200{ }^{\circ} \mathrm{C} T_{\mathrm{e}}$, but the film that was deposited at $400{ }^{\circ} \mathrm{C} T_{\mathrm{s}}$ and $15 \% P_{\mathrm{O} 2}$ has little variation. The maximum variation of transmittance of the sample reaches $39 \%$. There is tendency of bigger variation in transmittance for the sample with larger $P_{\mathrm{O} 2}$ deposition condition, when it was put into $200{ }^{\circ} \mathrm{C} T_{\mathrm{e}}$. All these properties of the films indicate that vanadium oxide films have good thermochromic behaviors and they are ideal TC materials.

\section{References}

[1] L. Ottaviano, A. Pennisi, F. Simone, A.M. Salvi, Opt. Mater. 27 (2) (November 2004) 307.

[2] D. Adler, Rev. Mod. Phys. 40 (1968) 714.

[3] S.M. Babulanam, T.S. Eriksson, G.A. Niklasson, C.G. Granqvist, Sol Energy Mater. 16 (1987) 347.

[4] S.H. Lee, H.M. Cheong, M.J. Seong, P. Liu, C.E. Tracy, A. Mascarenhas, J.R. Pitts, S.K. Deb, J. Appl. Phys. 92 (2002) 1893.

[5] S.H. Lee, H.M. Cheong, P. Liu, C.E. Tracy, Electrochem. Solid-State Lett. 6 (2003) A102.

[6] C.V. Ramana, R.J. Smith, O.M. Hussain, C.M. Julien, Mater. Sci. Eng., B 111 (2-3) (August 25 2004) 218.

[7] J. Cui, D. Da, W. Jiang, Appl. Surf. Sci. 133 (1998) 225.

[8] Z.S. El Mandouh, M.S. Selim, Thin Solid Films 371 (2000) 259.

[9] R.M. German, Powder Metallurgy Science, Metal Powder Industries Federation, Princeton, NJ, 1984.

[10] A. Surca, B. Orel, Electrochim. Acta 44 (1999) 3051.

[11] G. Grymonprez, L. Fiermans, J. Venink, Acta Crystallogr., A 33 (1977) 834.

[12] F. Theohald, R. Cabala, J. Bernard, J. Solid State Chem. 17 (1976) 431.

[13] Powder Diffraction File, Joint Committee on Powder Diffraction Standards, International Center for Diffraction Data, JCPDS 9-387, Swarthmore, 1986, PA.

[14] Y.S. Yoon, J.S. Kim, S.H. Choi, Thin Solid Films 460 (2004) 41

[15] V.V. Fomichev, P.I. Ukrainskaya, T.M. Ilyin, Spectrochim. Acta, Part A 53 (1997) 1833

[16] P. Jin, S. Tanemura, Thin Solid Films 281-282 (1996) 239.

[17] P. Clauws, J. Broeckx, J. Vennik, Phys. Status Solidi, B Basic Res. 131 (1985) 459

[18] K.V. Madhuri, B.S. Naidu, O.M. Hussain, M. Eddrief, C. Julien, Mater Sci. Eng., B 86 (2001) 165.

[19] B. Bootz, H. Finkenrath, G. Franz, N. Uhle, Solid State Commun. 13 (1973) 1477.

[20] I.L. Botto, M.B. Vassallo, E.J. Baran, G. Minelli, Mater. Chem. Phys. 50 (1997) 267. 